\title{
Cross-phosphorylation of bacterial serine/threonine and tyrosine protein kinases on key regulatory residues
}

\author{
Lei Shi ${ }^{1}$, Nathalie Pigeonneau ${ }^{2}$, Vaishnavi Ravikumar ${ }^{3}$, Paula Dobrinic ${ }^{4}$, Boris Macek ${ }^{3}$, \\ Damjan Franjevic ${ }^{4}$, Marie-Francoise Noirot-Gros ${ }^{2}$ and Ivan Mijakovic ${ }^{1 *}$ \\ SysBio, Department of Chemical and Biological Engineering, Chalmers University of Technology, Göteborg, Sweden \\ 2 UMR1319 Micalis, Institut National de Recherche Agronomique, Jouy-en-Josas, France \\ ${ }^{3}$ Proteome Center Tübingen, Interfaculty Institute for Cell Biology, University of Tübingen, Tübingen, Germany \\ ${ }^{4}$ Division of Biology, Faculty of Science, Zagreb University, Zagreb, Croatia
}

\section{Edited by:}

Christophe Grangeasse, Centre

National de la Recherche

Scientifique, France

Reviewed by:

Didier Soulat, Universitätsklinikum

Erlangen, Germany

Carsten Jers, Technical University of

Denmark, Denmark

\section{*Correspondence:}

Ivan Mijakovic, Systems and

Synthetic Biology, Chalmers

University of Technology, Kemivägen

10, Göteborg, SE-41296, Sweden

e-mail: ivan.mijakovic@chalmers.se
Bacteria possess protein serine/threonine and tyrosine kinases which resemble eukaryal kinases in their capacity to phosphorylate multiple substrates. We hypothesized that the analogy might extend further, and bacterial kinases may also undergo mutual phosphorylation and activation, which is currently considered as a hallmark of eukaryal kinase networks. In order to test this hypothesis, we explored the capacity of all members of four different classes of serine/threonine and tyrosine kinases present in the firmicute model organism Bacillus subtilis to phosphorylate each other in vitro and interact with each other in vivo. The interactomics data suggested a high degree of connectivity among all types of kinases, while phosphorylation assays revealed equally wide-spread cross-phosphorylation events. Our findings suggest that the Hanks-type kinases PrkC, PrkD, and YabT exhibit the highest capacity to phosphorylate other B. subtilis kinases, while the BY-kinase PtkA and the two-component-like kinases RsbW and SpollAB show the highest propensity to be phosphorylated by other kinases. Analysis of phosphorylated residues on several selected recipient kinases suggests that most cross-phosphorylation events concern key regulatory residues. Therefore, cross-phosphorylation events are very likely to influence the capacity of recipient kinases to phosphorylate substrates downstream in the signal transduction cascade. We therefore conclude that bacterial serine/threonine and tyrosine kinases probably engage in a network-type behavior previously described only in eukaryal cells.

Keywords: protein phosphorylation, bacterial protein kinase, protein kinase cross-talk, phosphorylation cascade, kinase activation

\section{INTRODUCTION}

In eukarya, protein kinases are known to participate in regulatory networks involved in cell cycle control, signal transduction, and other complex regulatory phenomena (Colinge et al., 2014). Most of the characterized eukaryal kinases exhibit two key functional features: each protein kinase phosphorylates a number of different protein substrates, and kinases phosphorylate and activate each other, thus participating in elaborate phosphorylation cascades (Marshall, 1994). Bacteria, whose cellular makeup is considered to be simplified and optimized for rapid bursts of growth, were usually thought not to possess such complicated kinase networks. The main sensing and signal transduction devices in bacteria are the so-called two-component systems, based on histidine/aspartate kinases (Goulian, 2010). The two component systems are very rapid signal transmission devices, linking environmental stimuli to gene expression. However, they operate mostly as linear signaling pathways, with essentially no cross-talk among different two-component systems (Podgornaia and Laub, 2013). Even in extended bacterial signaling systems, involving sequential phosphorylation of several two-component-like kinases, the flow of information remains linear (Burbulys et al., 1991). In addition to two-component systems, bacteria also possess serine/threonine (Pereira et al., 2011) and tyrosine protein kinases (Shi et al., 2014). While most bacterial serine/threonine kinases share the origin with their orthologs in eukarya, the bacterial tyrosine kinases do not (Shi et al., 2014). Nevertheless, they all exhibit some properties similar to their eukaryal counterparts. The capacity of bacterial serine/threonine and tyrosine kinases to phosphorylate multiple substrates has been clearly established. Examples of well-characterized bacterial kinases with multiple substrates include a number of Hanks-type serine/threonine kinases from Mycobacterium tuberculosis (Grundner et al., 2005; Molle and Kremer, 2010; Baer et al., 2014) and Bacillus subtilis (Absalon et al., 2009; Pietack et al., 2010; Ravikumar et al., 2014), as well as the tyrosine kinase PtkA from B. subtilis (Petranovic et al., 2009; Jers et al., 2010; Derouiche et al., 2013). By contrast, the capacity of bacterial protein kinases to phosphorylate each other is far less documented. Cross-phosphorylation among some Hanks-type serine/threonine kinases has recently been reported in M. tuberculosis (Baer et al., 2014). There is also evidence that Hanks-type serine/threonine kinases from B. subtilis can 
phosphorylate and activate a two-component histidine/aspartate kinase DegS (Jers et al., 2011). We have previously hypothesized that bacterial serine/threonine and tyrosine kinases, given their functional similarity to eukaryal kinases, might also constitute signal integration hubs by phosphorylating each other (Cousin et al., 2013). In order to test this hypothesis, we have elected to use B. subtilis as the system of study, due to the fact that this model organism possesses four distinct well characterized classes of bacterial serine/threonine and tyrosine kinases. These include two tyrosine kinases: PtkA (Jers et al., 2010) and PtkB (EpsB) (Gerwig et al., 2014); three Hanks-type serine/threonine kinases: PrkC (Madec et al., 2002), PrkD (Kobir et al., 2014), and YabT (Bidnenko et al., 2013); the twin-function kinase/phosphorylase HprK/P involved in carbon catabolite regulation (Hanson et al., 2002); and the three two-componentlike serine/threonine kinases: RsbT (Kang et al., 1998), RsbW (Yang et al., 1996), and SpoIIAB (Min et al., 1993). While all of these kinases have been characterized to varying degrees with respect to their physiological role and substrate phosphorylation, their capacity to phosphorylate each other has not been tested previously. Using in vitro phosphorylation assays with purified proteins, we demonstrated an extensive network of crossphosphorylation events involving all four classes of kinases. This cross-talk was also supported by interactomics data. In select cases, we have determined the residues phosphorylated on the "recipient" kinases by various "donor" kinases. The identity of these residues clearly suggests functional importance of crossphosphorylation events, influencing the activity of the "recipient" kinases.

\section{MATERIALS AND METHODS PROTEIN SYNTHESIS AND PURIFICATION}

The following kinase and substrate genes were PCR-amplified using the B. subtilis 168 genomic DNA as template and the primers listed in Table 1: $r s b T, h p r K, r s b W, p t k A, p r k D, y a b T$, prkC, spoIIAB, rsbV, spoIIAA, and $r s b S$. Site-directed mutagenic PCR (mutagenic primers listed in Table 1) was performed as described previously (Mijakovic et al., 2003), in order to inactivate the catalytic sites of kinases by replacing the catalytic residues: $r s b T$ N49A, hprK K159M, rsbW N53A, ptkA K59D, prkD K54D, yabT K55D, prkC K40D, and spoIIAB N50A. PCR products were inserted in the plasmid pQE-30 (Qiagen) to produce the 6xHis-tagged fusions of proteins. Strep-tagged versions of proteins were obtained using a pQE-30 vector with His6-tag replaced by a strep-tag (Jers et al., 2010). Escherichia coli K12 NM522 and M15 (expressing chaperonins GroEL/GroES) were used for vector construction and protein synthesis, respectively. Cells were routinely grown in LB medium supplemented with appropriate antibiotics when necessary (ampicillin $100 \mu \mathrm{g} / \mathrm{ml}$ and kanamycin $25 \mu \mathrm{g} / \mathrm{ml}$ ). Protein synthesis and purification were carried out as described previously (Mijakovic et al., 2003). Briefly, induction was performed at $\mathrm{OD}_{600}=0.6$ by adding $1 \mathrm{mM}$ IPTG. Cells were harvested $3 \mathrm{~h}$ later and disrupted by sonication. The 6xHis- or Strep-tagged proteins were purified from crude extracts using Ni-NTA (Qiagen), or Strep Tactin affinity chromatography (Novagen), respectively. For the insoluble proteins, PrkD K54D and YabT K55D, the inclusion bodies were
Table 1 | List of PCR primers used in this study.

\begin{tabular}{|c|c|}
\hline Name & Sequence \\
\hline$r s b T$ fwd & cgcggatccatgaacgaccaatcctgtgtaag \\
\hline rsbT rev & aaaactgcagctaccgaagccatttgatggcttg \\
\hline hprk fwd & cgcggatccatggcaaaggttcgcacaaaag \\
\hline hprk rev & aaaactgcagctattcttcttgttcaccgtcttc \\
\hline rsbW fwd & cgcggatccatgaagaataatgctgattac \\
\hline rsbW rev & aaaactgcagttagttagtttcgtagttttga \\
\hline ptkA fwd & cgcggatccatggcgcttagaaaaaacaga \\
\hline ptkA rev & aaaactgcagttattttgcatgaaattgtcc \\
\hline prkD fwd & cgggatccatggcattaaaacttctaaaaaaactgc \\
\hline prkD rev & aaaactgcagttatgtgaccgattgaatggcccg \\
\hline yabT fwd & cgcagatctatgatgaacgacgcttgacgagt \\
\hline yabT rev & ggactgcagtcacccacccgacttagccggtttct \\
\hline prkC fwd & gaagatctatgctaatcggcaagcggatcagcgggcg \\
\hline prkC rev & aaaactgcagttacaaaacccacggccactttttcttttgccg \\
\hline spollaB fwd & cgcggatccatgaaaaatgaaatgcaccttg \\
\hline spollaB rev & aaaactgcagttaattacaaagcgctttgct \\
\hline$r s b V$ fwd & cgcggatccatgaatataaatgttgatgtg \\
\hline rsbV rev & aaaactgcagtcattgcactccaccttct \\
\hline spoAA fwd & cgcggatccatgagccttggaattgacatg \\
\hline spoAA rev & aaaactgcagtcatgatgccaccccca \\
\hline$r s b S$ fwd & cgcggatccatgagacatccgaaaatcccga \\
\hline rsbs rev & aaaactgcagctattcccccaattcccgctt \\
\hline rsbT N49A fwd & ttagccagggctatttatttatatgccggcaaagggcagattg \\
\hline rsbT N49A rev & taaataaatagccctggctaattctgaaatagccgttgtaattc \\
\hline hprk K159M fwd & cggcgtcggaatgagcgaaacagcgctagagcttgtgaaaagag \\
\hline hprk K159M rev & ctgtttcgctcattccgacgccgcttttcctgtgatcagcacg \\
\hline rsbW N53A fwd & gcgtgcacagctgcggttcagcacgcttacaaagaagataaa \\
\hline rsbW N53A rev & gctgaaccgcagctgtgcacgcctcactgactgcgattttc \\
\hline ptkA K59D fwd & ggggaaggagattcaacaacggccgccaacctggctgtc \\
\hline ptkA K59D rev & cgttgttgaatctccttcccccggacaagccgatgtaat \\
\hline prkD K54D fwd & ttatgtcttagatcagcttcggccgacaaaagccaaaaag \\
\hline prkD K54D rev & gccgaagctgatctaagacataaggtgtttgagctagg \\
\hline YabT K55D fwd & tgttgccttagatgtgagtgatgacagcctgtctattac \\
\hline YabT K55D rev & catcactcacatctaaggcaacatgtccatctgatgtt \\
\hline prkC K40D fwd & agtcgcaattgatatcctgcggtttgactatgcaaatg \\
\hline prkC K40D rev & caaaccgcaggatatcaattgcgacttcacggtctagaatg \\
\hline spollAB N50A fwd & gctgtcacggctgcgattatccatggatatgaagagaactgtg \\
\hline spollAB N50A rev & gataatcgcagccgtgacagcctctgacacgactgttttgat \\
\hline
\end{tabular}

dissolved in the buffer containing $6 \mathrm{M}$ guanidine hydrochloride, $50 \mathrm{mM}$ Tris $\mathrm{pH} 7.5,100 \mathrm{mM} \mathrm{NaCl}, 5 \mathrm{mM} \mathrm{MgCl}_{2}$, and $5 \%$ glycerol. The purification was performed as mentioned before but in the buffer with additional $6 \mathrm{M}$ guanidine hydrochloride. To refold the proteins, the concentration of guanidine hydrocloride was lowered to $0.2 \mathrm{M}$. Purified proteins were desalted on PD-10 columns (GE Healthcare), and stored at $-80^{\circ} \mathrm{C}$ in $10 \%$ glycerol.

\section{IN VITRO KINASE CROSS-PHOSPHORYLATION PHOSPHORYLATION ASSAY}

Phosphorylation reactions were incubated in a buffer containing: $50 \mathrm{mM}$ Tris pH 7.5, $100 \mathrm{mM} \mathrm{NaCl}, 5 \mathrm{mM} \mathrm{MgCl}_{2}, 5 \%$ glycerol, 
A

\section{AD}

BD
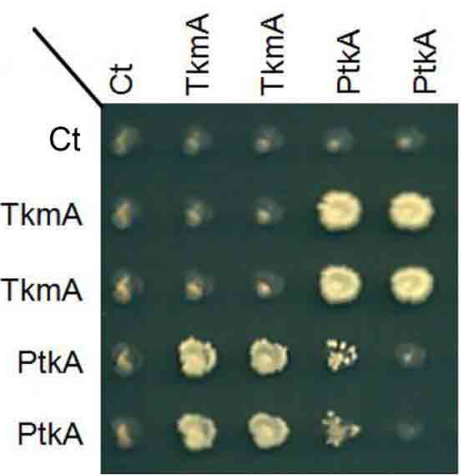

C

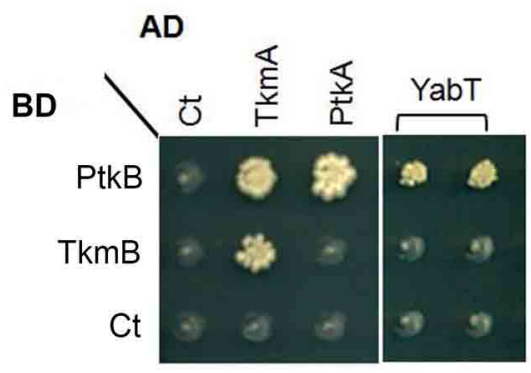

D

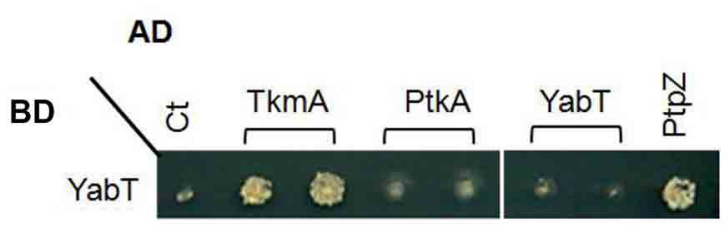

B

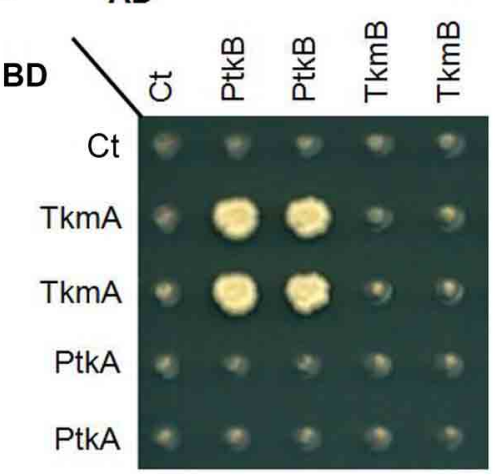

E AD

BD

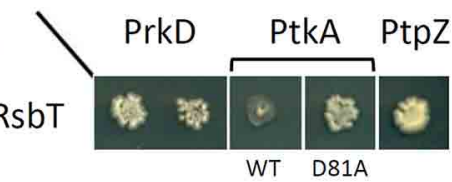

$\mathbf{F}$

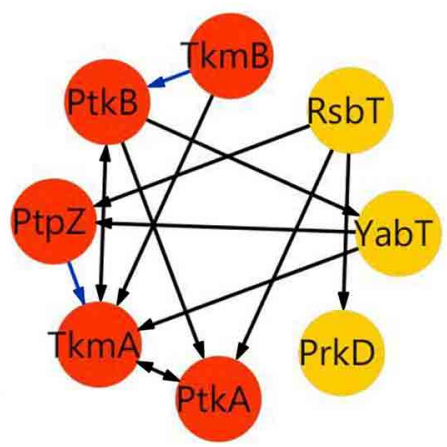

FIGURE 1 | Protein-protein interactions between some components of the tyrosine and serine/threonine signal transduction pathway. Interaction phenotypes were monitored by the ability of the yeast cells co-expressing a given bait (Gal4 BD-fusion) and prey (Gal4 AD-fusion) pair of proteins to grow on selective media, as described in the experimental procedures. (A) Reciprocal interactions between PtkA and its cognate modulator TkmA (fused to either AD or BD). (B) Interactions among components of the two BY-kinase systems: PtkA/TmkA (fused to BD) and PtkB/TkmB (fused to AD). (C-E) Examples of interactions between different families of kinases: (C) In addition of TkmA (here as positive control), PtkB (fused to BD) interacts with PtkA and YabT (fused to AD). (D) YabT (fused to BD) interacts with TkmA and PtpZ (fused to AD). (E) RsbT (fused to BD) interacts PrkD, PtpZ and catalytically inactive PtkA (D81A) (fused with AD). (F) A graphical representation of the interactions revealed by yeast two-hybrid. Proteins (nodes) are linked by edges (arrows) directed from bait to prey. Blue edges indicate additional interactions found after yeast two-hybrid screenings of the B. subtilis genomic library (Shi et al., unpublished results).
$50 \mu \mathrm{M}$ ATP, and $20 \mu \mathrm{Ci} / \mathrm{mmol}[\gamma-32 \mathrm{P}]$-ATP. Each phosphorylation reaction contained one wild type active kinase and one catalytically deficient kinase. The assay was assembled using the following final protein concentrations: $3 \mu \mathrm{M}$ RsbT WT, $3 \mu \mathrm{M}$ HprK WT, $5 \mu \mathrm{M}$ RsbW WT, $5 \mu \mathrm{M}$ PtkA WT with $5 \mu \mathrm{M}$ TkmA, $2 \mu \mathrm{M}$ PrkD WT, $1 \mu \mathrm{M}$ YabT WT, $1 \mu \mathrm{M}$ PrkC WT, $5 \mu \mathrm{M}$ SpoIIAB WT, $9 \mu \mathrm{M}$ RsbT N49A, $4 \mu \mathrm{M}$ HprK K159M, $9 \mu \mathrm{M}$ RsbW N53A, $3 \mu \mathrm{M}$ PtkA K59D, $3 \mu \mathrm{M}$ PrkD K54D, $2 \mu \mathrm{M}$ YabT K55D, $3 \mu \mathrm{M}$ PrkC K40D, $9 \mu \mathrm{M}$ SpoIIAB N50A. Phosphorylation reactions were incubated for $1 \mathrm{~h}$ at $37^{\circ} \mathrm{C}$, stopped by boiling at $100^{\circ} \mathrm{C}$, and samples were separated on an $8-12 \%$ SDSpolyacrylamide gel. Autoradiography signals were revealed using the FUJI phosphoimager.

\section{IN VITRO PHOSPHORYLATION OF HPr}

Proteins $(2 \mu \mathrm{M}$ PrkD, $2 \mu \mathrm{M}$ HprK/P, $6 \mu \mathrm{M}$ HPr) were incubated in a buffer containing $50 \mathrm{mM}$ Tris $\mathrm{pH} 7.5,100 \mathrm{mM} \mathrm{NaCl}, 5 \mathrm{mM}$ $\mathrm{MgCl} 2,5 \%$ glycerol, and $1 \mathrm{mM}$ ATP to perform the phosphorylation reactions. The reactions were incubated for $1 \mathrm{~h}$ at $37^{\circ} \mathrm{C}$, stopped by boiling at $100^{\circ} \mathrm{C}$, and samples were separated on an $8-12 \%$ SDS-polyacrylamide gel. Signals from phosphorylated protein have been revealed by Pro-Q ${ }^{\circledR}$ Diamond phosphoprotein stain (Life Technologies). After two fixation steps in a solution containing 50\% methanol and 10\% acetic acid (30 min each), the gel was stained by the Pro-Q ${ }^{\circledR}$ Diamond phosphoprotein stain for $90 \mathrm{~min}$. The gel was de-stained by three 30 -min washes in a solution containing $20 \%$ acetonitrile and $50 \mathrm{mM}$ sodium acetate, 


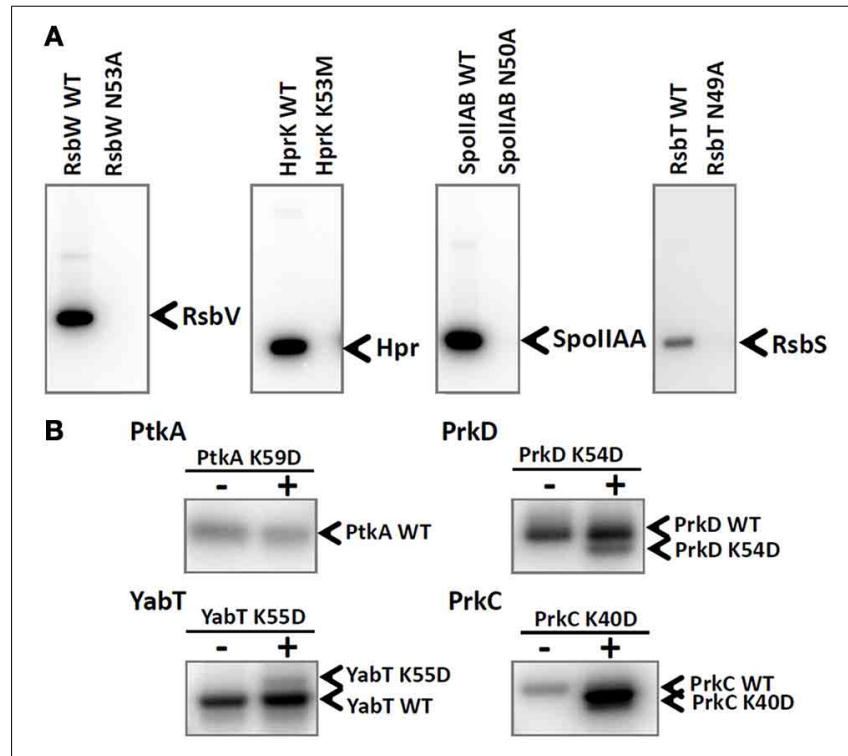

FIGURE 2 | Inactivation of catalytic residues in all tested $B$. subtilis kinases. (A) Autoradiography images of the in vitro phosphorylation assays of RsbV, Hpr, SpollAA, and RsbS phosphorylated by their respective kinases: RsbW, HprK, SpollAB, and RsbT. Final protein concentrations in the assays were: $10 \mu \mathrm{M}$ RsbV with $5 \mu \mathrm{M}$ RsbW WT or RsbW N53A, $10 \mu \mathrm{M}$ Hpr with $5 \mu \mathrm{M}$ HprK/P WT or HprK K53M, $10 \mu \mathrm{M}$ SpollAA with $1 \mu \mathrm{M}$ SpollAB WT or SpollAB N50A, $3 \mu \mathrm{M}$ RsbS with $3 \mu \mathrm{M}$ RsbT WT or RsbT N49A. Bands corresponding to phosphorylated substrates are indicated by arrows. (B) Autoradiography images of intermolecular autophosphorylation assays (using incorporation of ${ }^{32} \mathrm{P}$ ) between wild type kinases PtkA, PrkC, PrkD, and YabT and their respective mutated versions PtkA K59D, PrkC K40D, PrkD K54D, and YabT K55D. Final protein concentrations in the in vitro phosphorylation assay were: $1 \mu \mathrm{M}$ PtkA WT, $1 \mu \mathrm{M}$ TkmA, $1 \mu \mathrm{M}$ PtkA K59D, $1 \mu \mathrm{M}$ PrkD WT, $1.5 \mu \mathrm{M}$ YbdM K54D, $0.5 \mu \mathrm{M}$ YabT WT, $0.5 \mu \mathrm{M}$ YabT K55D, $0.5 \mu \mathrm{M}$ PrkC WT, and 0.6 $\mu \mathrm{M}$ PrkC K40D. Wild type proteins were present on all lanes, and the presence or absence of mutant proteins is indicated with +/- above each lane. In order to be able to separate the WT kinases from the mutant versions, PtkA WT, PrkD WT, YabT K55D, and PrkC WT were fused with a $6 x$ His-tag and the respective mutant versions were Step-tagged fusions. Bands corresponding to phosphorylated kinases are indicated by arrows.

$\mathrm{pH}$ 4.0. The gel was washed twice with ultrapure water for $5 \mathrm{~min}$, before scanning.

\section{IDENTIFICATION OF PHOSPHORYLATED RESIDUES BY MASS SPECTROMETRY}

In vitro phosphorylation reactions of PrkD K54D, YabT K55D, PtkA K59D, SpoIIAB N50A, and HprK K159M phosphorylated by PrkC, PtkA, PrkC, PrkD, and PrkD, respectively, were performed as described above, with the only difference of using only non-radioactive ATP. Denaturation of the samples was performed by buffer exchange to $6 \mathrm{M}$ urea and $2 \mathrm{M}$ thiourea in $10 \mathrm{mM}$ Tris$\mathrm{HCl} \mathrm{pH}$ 8.0. Mass spectrometry analysis of phosphorylation sites was performed essentially as described previously (Derouiche et al., 2013). Briefly, in-solution digestion with trypsin was followed by phosphopeptide enrichment. Phosphopeptide analysis was performed on a Proxeon Easy-LC system (Proxeon Biosystems) coupled to an LTQ-Orbitrap-XL (Thermo Fisher Scientific) equipped with a nanoelectrospray ion source (Proxeon
Biosystems). The five most intense precursor ions were fragmented by activation of neutral loss ions at $-98,-49$, and -32.6 relative to the precursor ion (multistage activation). Acquired MS spectra were processes with MaxQuant software package (version 1.2.2.9). False discovery rates at peptide, phosphorylation site, and protein group level were set to $1 \%$. Within the modified peptide, phosphorylation events detected with localization probability of at least 0.75 were considered as assigned to a specific residue.

\section{YEAST TWO-HYBRID ASSAYS}

Kinase-kinase binary interactions between various kinases and phosphatases were assessed essentially as described previously (Noirot-Gros et al., 2002). The genes encoding the BY-kinases (PtkA, PtkA) Hanks-type serine/threonine-kinases (PrkC, PrkD, YabT), two-component-like serine-kinases (SpoIIAB, RsbT, and RsbW), BY-kinase modulators (TkmA, TkmB), and the phosphotyrosine - and phosphoserine/threonine protein phosphatases (PtpZ, SpoIIE) were inserted in the pGBDU and pGAD yeast two-hybrid vectors to generate in-frame fusions with the DNA-binding domain (BD) and the activating domain (AD), respectively, of Gal4 (James et al., 1996). The pGBD and pGAD constructs were used to transform yeast (a) and $(\alpha)$ strains, respectively. Binary matrix of interactions was made by mixing haploid cells of complementary mating types, harboring various BD-kinase and AD-kinase fusions, in a 96 wells format. Interaction phenotypes were assessed by the ability of the diploid forms to grow on selective media depleted for histidine. Positive interactants were identified by DNA sequencing.

\section{SEOUENCE ALIGNMENTS AND 3D-STRUCTURE MODELING}

Sequence alignments were performed using MAFFT (Katoh and Toh, 2008). Structural models of PrkD (residues 17-253), YabT (residues 25 to 268), PtkA (residues 10 to 226), and HprK (residues 6 to 299) were obtained using the SWISS-MODEL (Bordoli et al., 2009). The residues 227 and 228 of PtkA were added to the structure manually to cover the autophosphorylation site Y228. Both PrkD and YabT were modeled based on PknB from M. tuberculosis (1mruB) (Young et al., 2003) as template. PtkA was modeled based on CapB from Staphylococcus aureus (2vedB) (Olivares-Illana et al., 2008), and HprK/P was modeled based on HprK/P from Staphylococcus xylosus (Márquez et al., 2002) (1ko7A). SpoIIAB structure has been experimentally resolved (1thnC) (Masuda et al., 2004).

\section{RESULTS AND DISCUSSION CROSS-PHOSPHORYLATION OF BACILLUS SUBTILIS SERINE/THREONINE AND TYROSINE KINASES}

In this study we set out to explore the possibility of crossphosphorylation among eight $B$. subtilis protein kinases: PrkC, PrkD, YabT, PtkA, HprK/P, RsbT, RsbW, and SpoIIAB. The second BY-kinase PtkB (EpsB) (Gerwig et al., 2014) was left out from in vitro studies due to known solubility issues (Mijakovic et al., 2003). First we explored the capacity of the kinases to physically interact with each other, by performing two-hybrid screens using individual kinases as baits (Figure 1). An interaction detected 


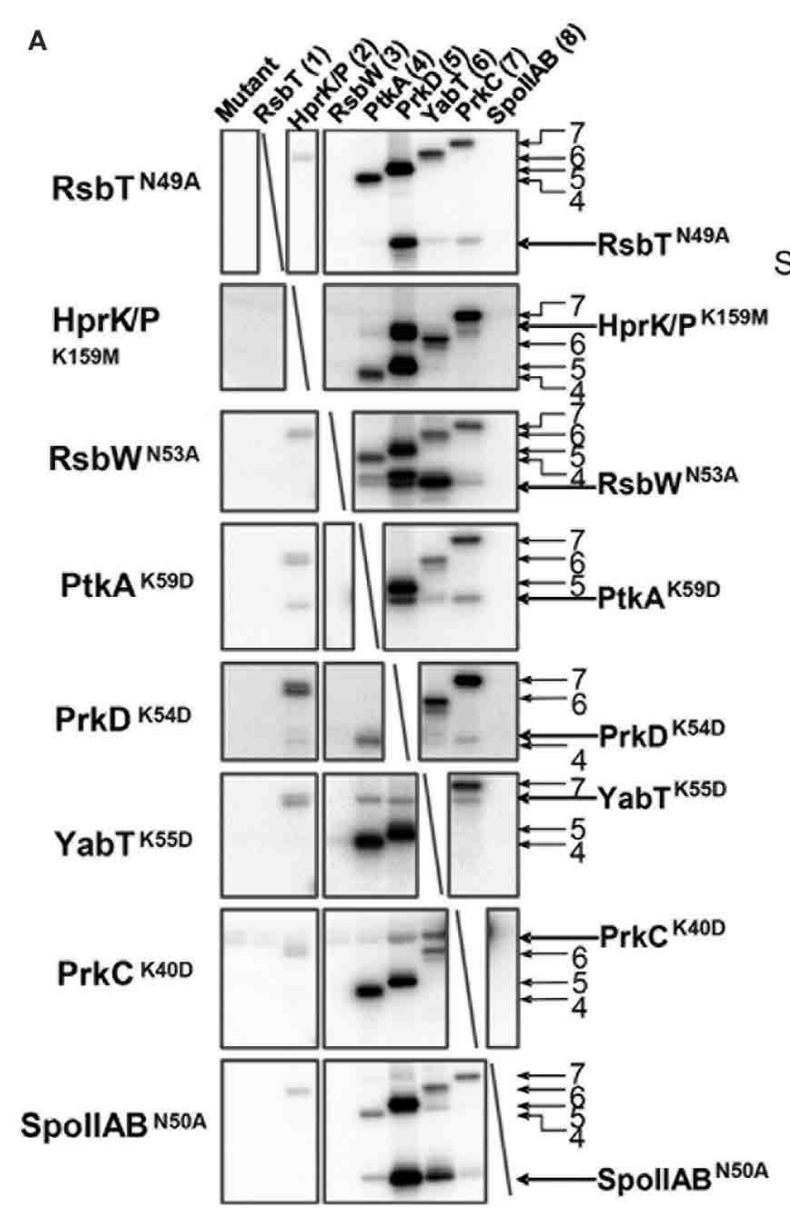

B

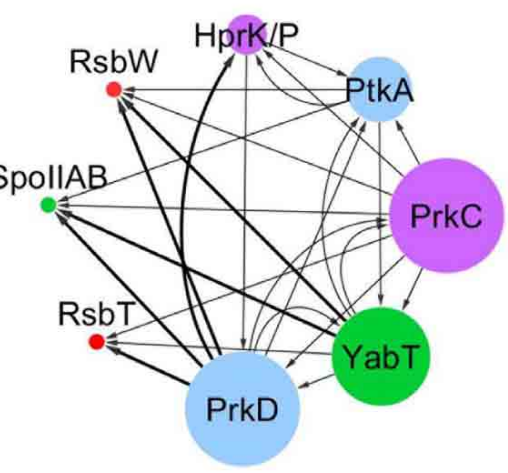

C

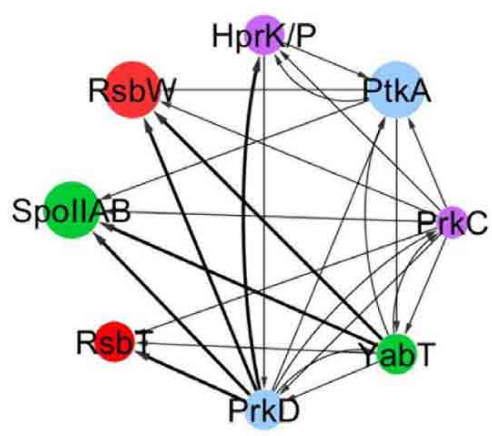

FIGURE 3 | In vitro phosphorylation assay showing

cross-phosphorylation among kinases. Catalytically deficient protein kinase mutants carrying a substitution of the catalytic residue (indicated in each row) have been assayed pair-wise for phosphorylation by 8 different wild type kinases (indicated in columns and numbered) in the presence of ${ }^{32} \mathrm{P}-\gamma$-ATP. Signals from phosphorylated kinases have been revealed by autoradiography. First lane of each gel is the inactivated kinase substrate alone as a negative control. Bands corresponding to autophosphorylation of wild type kinases (numbered) and

phosphorylation of mutated kinase substrates are indicated by arrows.
(B,C) Graphical overview of the results shown in (A). Panel (B) presents the outgoing degree of connectivity (number of phosphorylation reactions catalyzed by the kinase), and panel (C) shows the incoming degree of connectivity (number of phosphorylation reactions underwent by the kinase). The size of the nodes refers to the degree of connectivity of each kinase. Color of nodes refers to the physiological condition for up-regulation of kinase expression based on Nicolas et al. (2012): sporulation (green), germination (purple) oxidative stress (red), biofilm formation and swarming (blue). Connecting line width illustrates relative phosphorylation efficiency. between two proteins in both directions, i.e., irrespective of which one of them is used as a bait or prey, is termed reciprocal. An interaction is termed non-reciprocal when it has been detected with only one bait-prey configuration, but not the other. In our assay, we detected a reciprocal interaction between the BY-kinase PtkA and its cognate modulator TkmA, first described by Mijakovic et al. (2003) (Figure 1A). Next, we detected a reciprocal interaction between $\mathrm{TkmA}$ and the second BY-kinase PtkB (Figures 1B,C). There were also two nonreciprocal interactions: that of PtkA and $\mathrm{PtkB}$ and $\mathrm{TkmA}$ and TkmB (Figure 1C). The BY-kinases PtkA and PtkB were connected to the Hanks-type serine/threonine kinase YabT either via a direct interaction (PtkB, Figure 1C) or via an interaction with the PtkA modulator TkmA (Figure 1D). YabT also interacted with the phosphotyrosine-protein phosphatase PtpZ, known to dephosphorylate PtkA substrates (Mijakovic et al., 2005). The two-component-like kinase RsbT interacted directly with the BY-kinase PtkA and its cognate phosphatase PtpZ (Figure 1E). Interestingly, the RsbT did not interact with the wild-type PtkA, but interacted with the catalytically inactive mutant D81A. A direct interaction was also observed between RsbT and the Hanks-type kinase PrkD (Figure 1E). Hanks-type kinases YabT and PrkD also interacted directly with the sensory histidine kinase DegS which they are known to phosphorylate (Jers et al., 2011) (data not shown). Another link between tyrosine phosphorylation systems and the two-component systems was established through a binary interaction involving the phosphotyrosine-protein phosphatase YwlE (Musumeci et al., 2005) and the two-component response regulator YxdJ (Joseph et al., 2004) (data not shown). These findings suggest that 
A
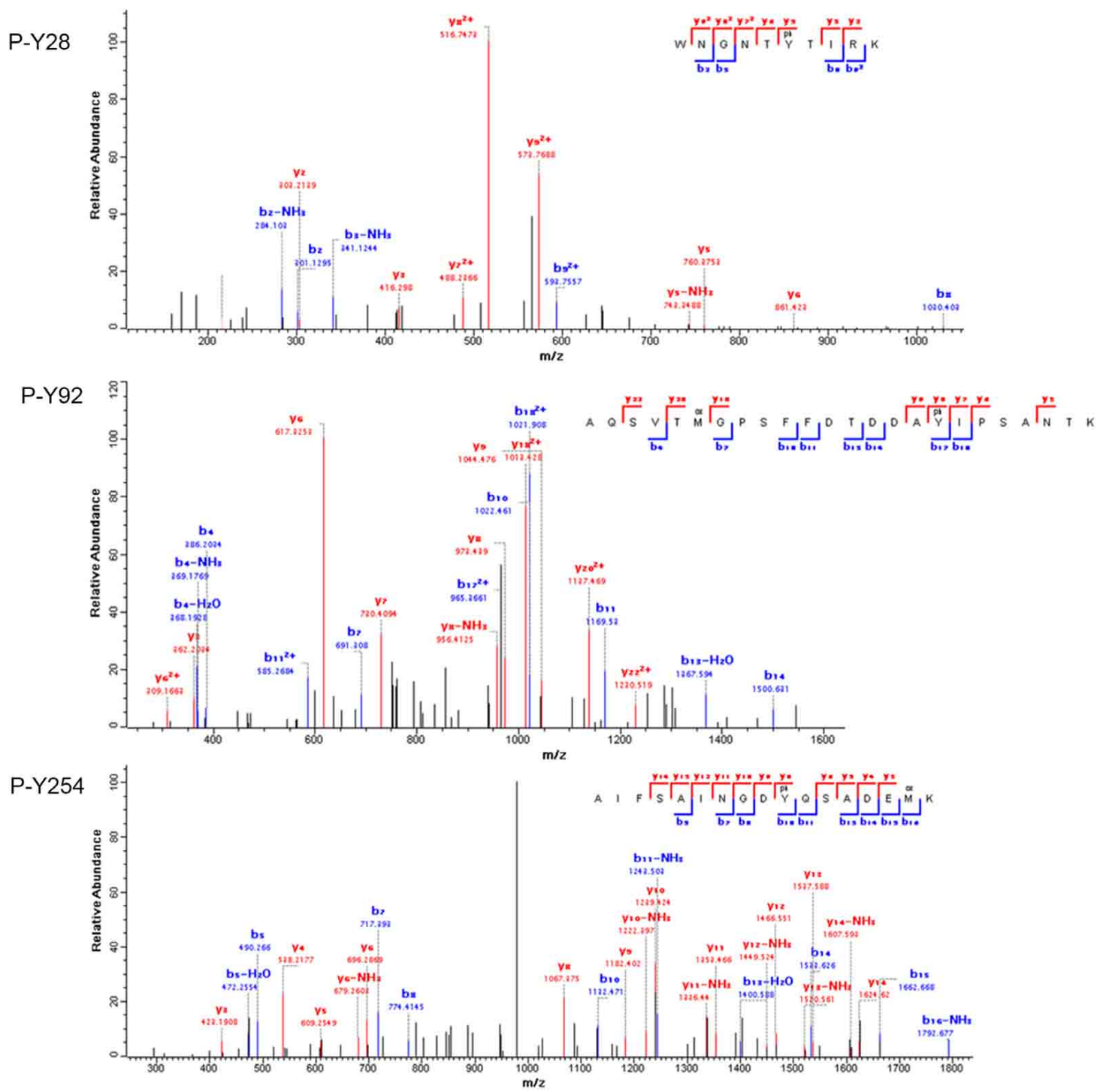

B

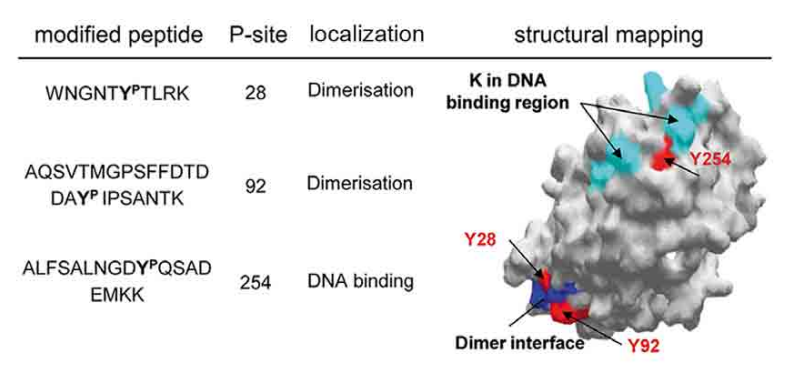

FIGURE 4 | Phosphorylation of YabT by PtkA. (A) Identification of phosphorylated residues by mass spectrometry. Fragmentation spectra for the three modified peptides, bearing the phosphorylated tyrosine residues 28, 92, and 254, are shown. (B) Mapping of the phosphorylated residues on the structural model of YabT obtained by SWISS-MODEL (surface representation). The phosphorylated residues are shown in red, residues in blue are associated with the region involved in the formation of dimers in YabT and in PknB (Rakette et al., 2012) and the residues in cyan represent the DNA binding region of YabT (Bidnenko et al., 2013). (C) Alignment of B. subtilis YabT, PrkC, and PrkD sequences with Hanks-type kinase homologs:
C

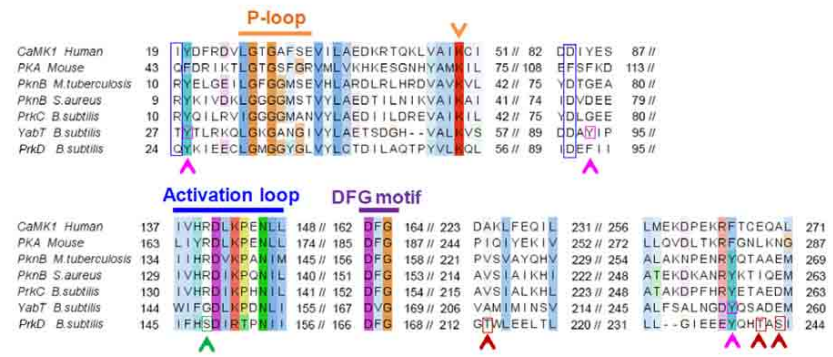

the kinase domains of calcium/calmodulin-dependent protein kinase (CaMK1, human), protein kinase A (PKA, mouse), PknB from M. tuberculosis and Staphylococcus aureus. The P-loop, catalytic site (K), catalytic loop and the DFG motif are indicated (Young et al., 2003). The residues R9 and D75 in $\mathrm{PknB}$ of $\mathrm{S}$. aureus which are involved in dimer formation (Rakette et al., 2012) are indicated with blue boxes. For YabT, the residues Y28, Y92 and Y254, which are phosphorylated by PtkA, are indicated with pink boxes and arrows. For PrkD, the residues T213, T241, and S243, which is phosphorylated by PrkC, are indicated with red boxes and arrows, and the S148, which is phosphorylated by HprK/P, is indicated with a green box and arrow. 


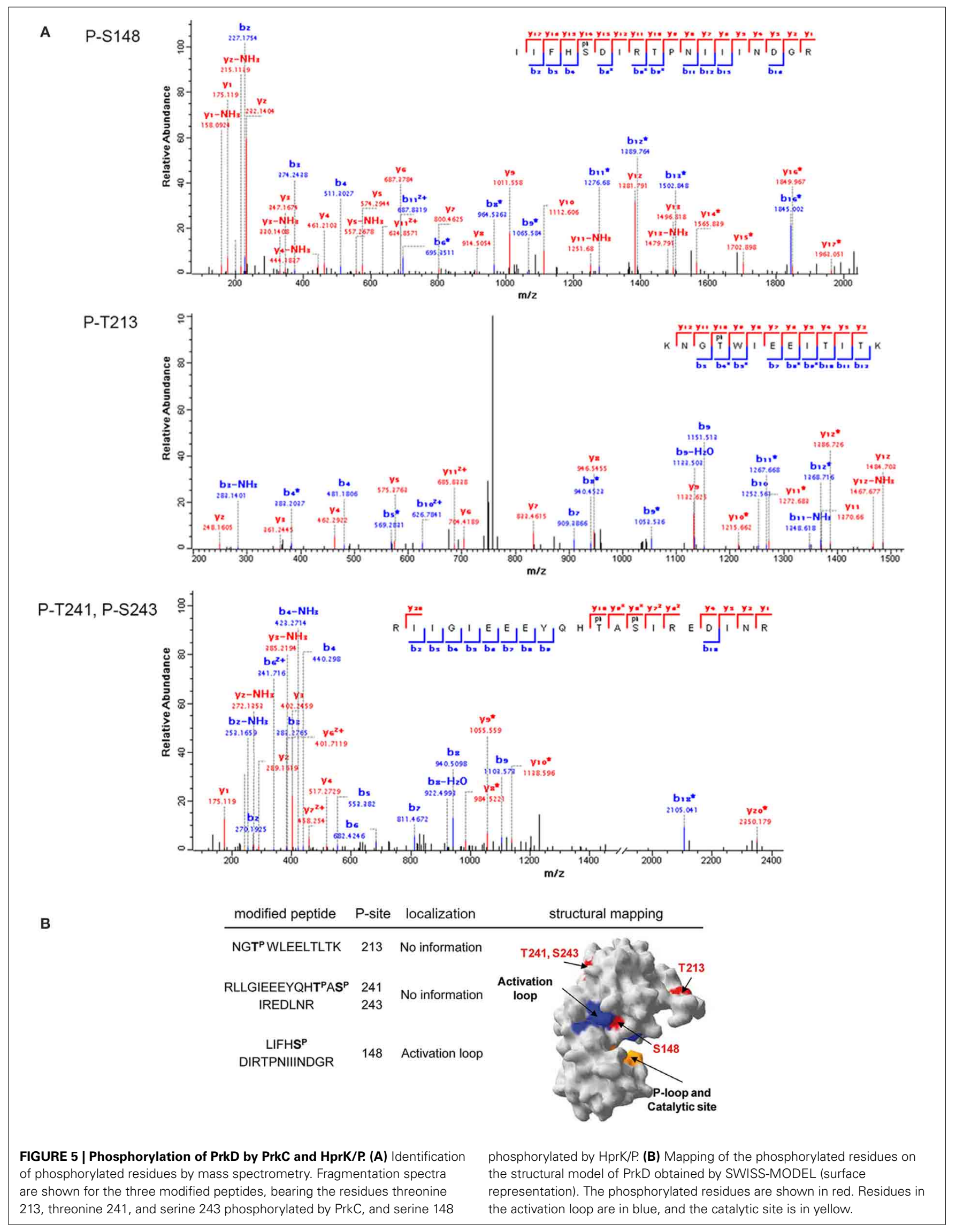




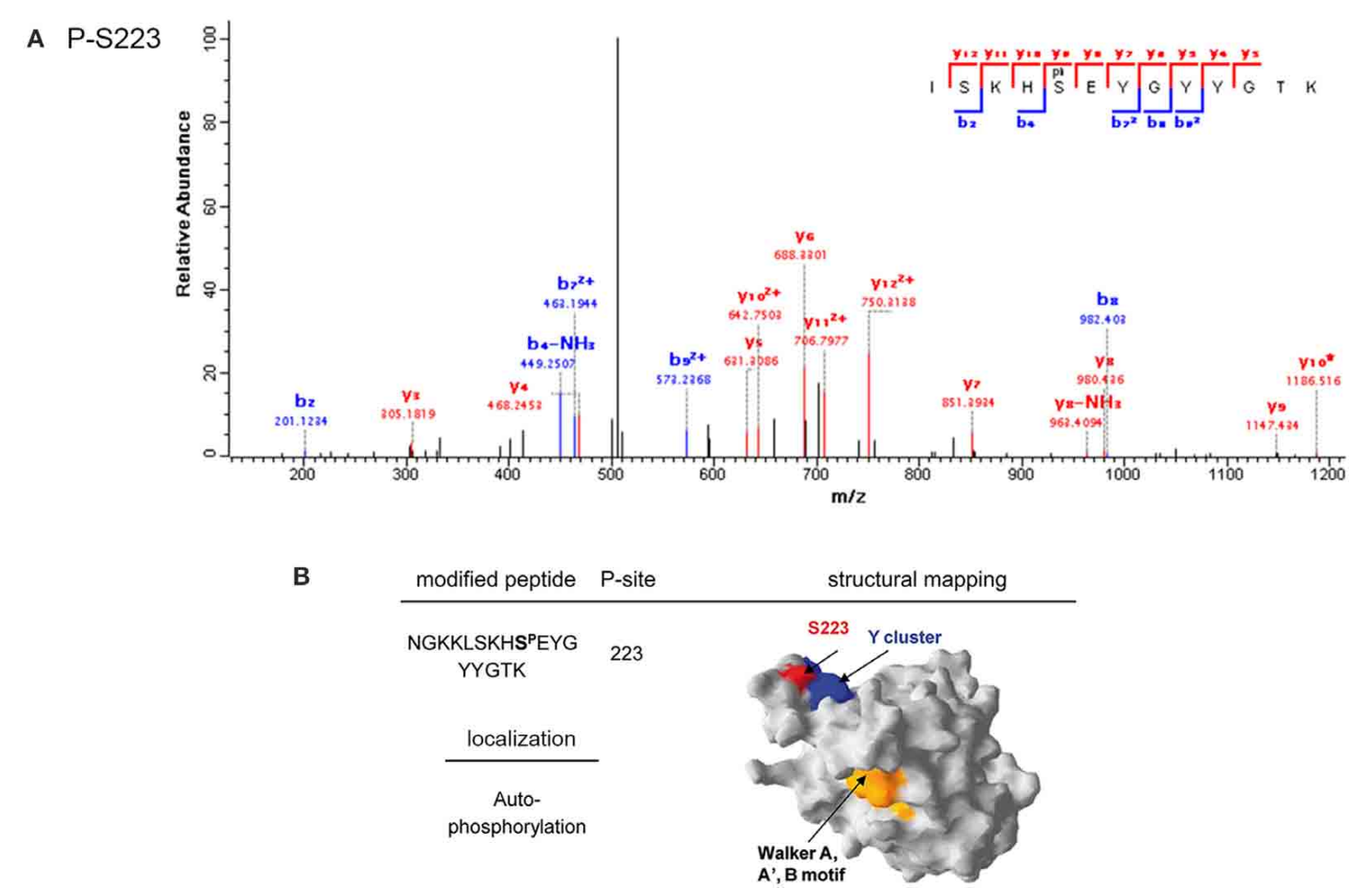

FIGURE 6 | Phosphorylation of PtkA by PrkC. (A) Identification of the phosphorylated residue by mass spectrometry. Fragmentation spectrum for the peptide bearing the phosphorylated serine residue 223 is shown. (B) Mapping of the phosphorylated residues on the structural model of
PtkA obtained by SWISS-MODEL (surface representation). The phosphorylated residue is shown in red. Residues in the C-terminal autophosphorylated tyrosine cluster are shown in blue, and the PtkA active site is in yellow. physical interactions exist among three different classes of kinases: Hanks-type kinases, BY-kinases, and two-component systemslike kinases. The bi-functional kinase/phosphorylase HprK/P did not appear to interact with other kinases in the two-hybrid assay (data not shown). A weak growth phenotype, featuring a possible PtkA self-interaction was also observed in only one of the two tested AD-PtkA fusions (Figure 1A). This could be explained by differential levels of expression of the AD-PtkA fusions in the two different haploid yeast strains.

Next, we explored the capacity of purified protein kinases to phosphorylate each other. We first purified mutant versions of each kinase with inactivated catalytic residues. Since several of the studied kinases, HprK/P, RsbT, RsbW, and SpoIIAB, do not autophosphorylate, we tested their catalytically inactive mutant versions (HprK/P K53M, RsbT N49A, RsbW N53A, SpoIIA N50A) on their respective substrates: Hpr, RsbS, RsbV, and SpoIIAA (Figure 2A). All mutant kinases were unable to phosphorylate the substrates, indicating that the catalytic site inactivation has been completed successfully. Next, we examined the capacity for intermolecular autophosphorylation for the autophosphorylating kinases PtkA, PrkC, PrkD, and YabT (Figure 2B). In case of PrkC, PrkD and YabT, intermolecular autophosphorylation was indeed detected. The mutant versions PrkC K40D, PrkD K54D, and YabT K55D were all phosphorylated by their respective wild type counterparts, which is consistent with the know mode of activation of Hanks-type kinases through a binary interaction (Barthe et al., 2010). This signal of phosphorylation on PrkC K40D was particularly strong, suggesting that this kinase is very efficient in intermolecular autophosphorylation. Since PrkC is the only Hanks-type kinase in B. subtilis that possesses an extracellular ligand-binding domain, it seems plausible that its mode of activation follows the canonical trans-phosphorylation triggered by ligand-induced dimerization at the membrane. By contrast, YabT is known to be activated by binding DNA at the asymmetric septum during spore development (Bidnenko et al., 2013) and for the soluble PrkD, the activation mechanism is not known. For the BY-kinase PtkA we could not detect trans-autophosphorylation, which is in agreement with our previous findings (Mijakovic et al., 2003). For the remaining kinases, HprK/P, RsbT, RsbW and SpoIIAB, intermolecular autophosphorylation was not observed, as expected (data not shown).

The catalytically deficient kinases were then subjected to cross-phosphorylation by the entire set of wild type kinases, in an eight by eight matrix experiment (Figure 3A). The reactions were assembled based on the assumption that kinases are present in roughly equimolar concentrations in the B. subtilis cell (Nicolas et al., 2012). Small variations in the final kinase concentrations in the assay are a result of optimization to simultaneously visualize signals of kinases migrating close 


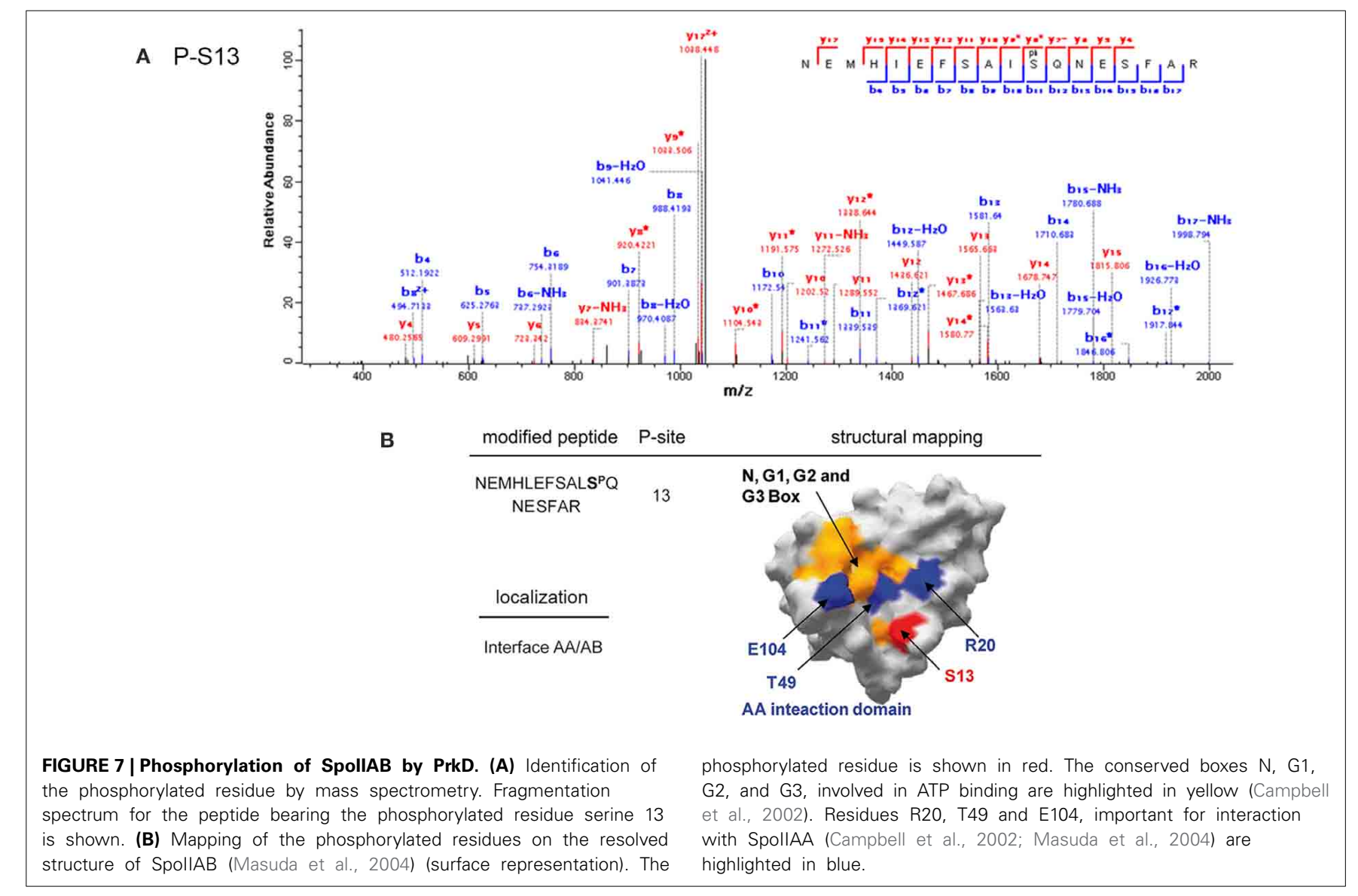

to each other in SDS-PAGE. In this assay a number of cross phosphorylation events were detected. The results from the crossphosphorylation assay are summarized in the kinase-kinase network (Figures 3B,C). Two main classes emerge with respect to propensity for cross-phosphorylation. The autophosphorylating kinases PrkD, PrkC, YabT, and PtkA (Figure 2A) exhibited a strong tendency to phosphorylate other kinases, i.e., they possess a high degree of outgoing connectivity (Figure 3B). PtkA and YabT reciprocally phosphorylated each other in agreement with their capacity to physically interact (Figure 1). The three kinases with the highest degree of incoming connectivity (i.e., propensity to be phosphorylated by other kinases) were SpoIIAB, RsbW, and PtkA (Figure 3C). The two-component-like kinases RsbW and SpoIIAB were found to be efficiently phosphorylated by the Hanks-type kinases PrkD and YabT. PrkD also efficiently phosphorylated HprK/P and RbsT. The latter observation correlates with our identification of the RsbT-PrkD interaction in vivo (Figure 1).

These findings suggest that cross-talk among different families of bacterial kinases is not only possible, but might in fact be quite common. As indicated in the previous section, our protein-protein interaction, and kinase-cross phosphorylation datasets exhibit a significant overlap. Connections between kinases which are supported by both approaches should be considered with a higher degree of confidence, but others should not be discarded. We have recently demonstrated that interactomics and phosphoproteomics datasets, while each detecting many kinase-substrate connections, fail to detect them all (Shi et al., unpublished results). Therefore, such complementary approaches should be combined whenever possible.

\section{KINASE CROSS-PHOSPHORYLATION OCCURS AT KEY REGULATORY RESIDUES}

To explore the potential consequences of cross-phosphorylation on the recipient kinase function, we focused on several cases representing different types of cross-talk and identified the phosphorylated residues on recipient kinases by mass spectrometry. The examined "recipient" kinases: PtkA, PrkD, YabT, SpoIIAB, and $\mathrm{HprK}$, comprised representatives of all four kinase types. After identifying the phosphorylation sites, we mapped them onto the resolved kinase structures or homology-based structural models, in order to evaluate the possible impact of cross-phosphorylation on the recipient kinase function.

First we examined the phosphorylation of the Hanks-type kinase YabT by the BY-kinase PtkA. We detected three phosphorylated tyrosine residues on YabT (Figure 4A). Two of them (Y28 and Y92) are located in the cluster of conserved residues involved in dimer formation (Rakette et al., 2012) (Figure 4B). The third one (Y254) is embedded within a lysine/arginine-rich region essential for DNA binding by YabT, which is known to stimulate the kinase activity (Bidnenko et al., 2013) (Figure 4B). A negative charge introduced by phosphorylation at Y254 is likely 


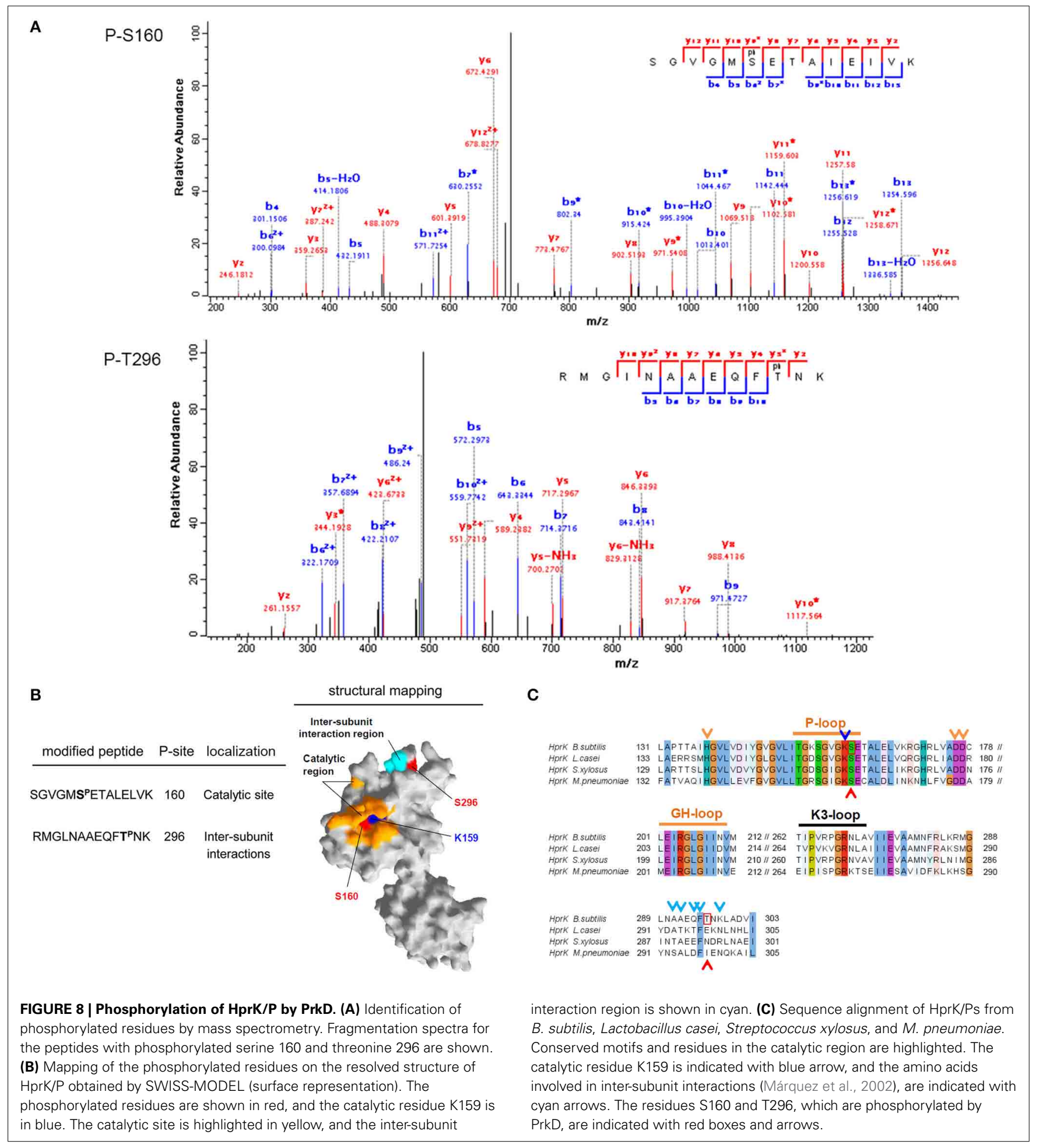

to affect the YabT interaction with DNA, while phosphorylation at Y28 and Y92 might affect dimerization of the kinase. These findings clearly suggest that PtkA-dependent phosphorylation of YabT could modulate the activity of the recipient kinase. Sequence alignment of YabT with other Hanks-type serine/threonine kinases shows that the residues Y28 and Y254 in YabT are highly conserved (Figure 4C), suggesting that the regulatory mechanism involving their phosphorylation could be widely conserved.

PrkD is a cytosolic Hanks-type serine/threonine kinase with no transmembrane helix. For its transmembrane paralogs, PrkC and YabT, the activation mechanism by respective binding of muropeptides (Shah et al., 2008) and DNA (Bidnenko et al., 2013) 
has been clearly established. By contrast, the activation mechanism of PrkD is not known. We have detected that PrkD can be phosphorylated by PrkC and HprK/P. Phosphorylation of PrkD by PrkC occured on residues T213, T241, and S243 (Figure 5A), which are in the catalytic domain, but distant from the active site (Figure 5B). Any putative regulatory potential of these phosphorylation events can not be deduced directly. However, HprK/P phosphorylated PrkD on the residue S148 (Figure 5A) in the activation loop, with a very probable consequence of stimulating the PrkD kinase activity (Figure 5B). The residue serine 148 is not conserved in Hanks-type kinases (Figure 4C). The structure of PrkD, lacking the transmembrane helix, is also unusual for bacterial Hanks-type kinases. This configuration with another kinase phosphorylating the activation loop of PrkD (usually accomplished by intermolecular autophosphorylation leading to activation of canonical Hanks-type kinases) could represent an idiosyncratic mechanism to activate this cytosolic kinase.

The BY-kinase PtkA was phosphorylated by PrkC at S223 (Figure 6A). This residue is positioned in the immediate vicinity of the C-terminal tyrosine cluster, containing PtkA autophosphorylation sites (Y225, Y227, and Y228) (Figure 6B). BY-kinase autophosphorylation on these tyrosines is known to trigger the dissociation of the activator-bound octameric ring (OlivaresIllana et al., 2008). Interestingly, we have previously observed that PtkA autophoshorylation at Y228 is strongly enhanced in vivo in the $\Delta p r k C$ strain (Ravikumar et al., 2014). This suggests that PrkC-dependent phosphorylation of PtkA at S223 could inhibit its autophosphorylation, and thus regulate its oligomerization state and interaction with the activator TkmA (Mijakovic et al., 2003).

The two-component system-like serine/threonine kinase SpoIIAB was phosphorylated by PrkD at S13 (Figure 7A). This residue is located on the interface interacting with the anti-antisigma factor SpoIIAA (Figure 7B), close to the residues R20, T49, and E104, which are known to be essential for this interaction (Masuda et al., 2004). SpoIIAA is also an inhibitor of the SpoIIAB kinase activity, and must dissociate from the complex in order for the kinase to be active. Phosphorylation of SpoIIAB by PrkD at S13 might be an alternative route to destabilize the SpoIIAA/SpoIIAB complex, and its phosphorylation is therefore likely to have a regulatory role.

Finally, the bifunctional HprK/P was phosphorylated by PrkD at residues S160 and S296 (Figure 8A). S296 is situated in the region necessary for subunit interactions in the HprK/P hexamer (Márquez et al., 2002) (Figure 8B), but it is not conserved (Figure 8C). By contrast, the phosphorylated $\mathrm{S} 160$ is situated adjacent to the catalytic residue K159 and is highly conserved (Figures 8B,C). We speculated that its phosphorylation is very likely to affect the catalytic activity of $\mathrm{HprK} / \mathrm{P}$, which depends on the positively charged catalytic lysine. In order to test this assumption, we phosphorylated $\mathrm{HprK} / \mathrm{P}$ with $\operatorname{PrkD}$ in vitro, and then compared the capacity of phosphorylated vs. non-phosphorylated HprK/P to phosphorylate its substrate $\mathrm{HPr}$ (Figure 9). The presence of PrkD in the phosphorylation assay significantly diminished the capacity of HprK/P to phosphorylate HPr. The Pro-Q ${ }^{\circledR}$ Diamond-stained signal from phosphorylated HprK/P comprises the pre-existing artificial autophosphorylation

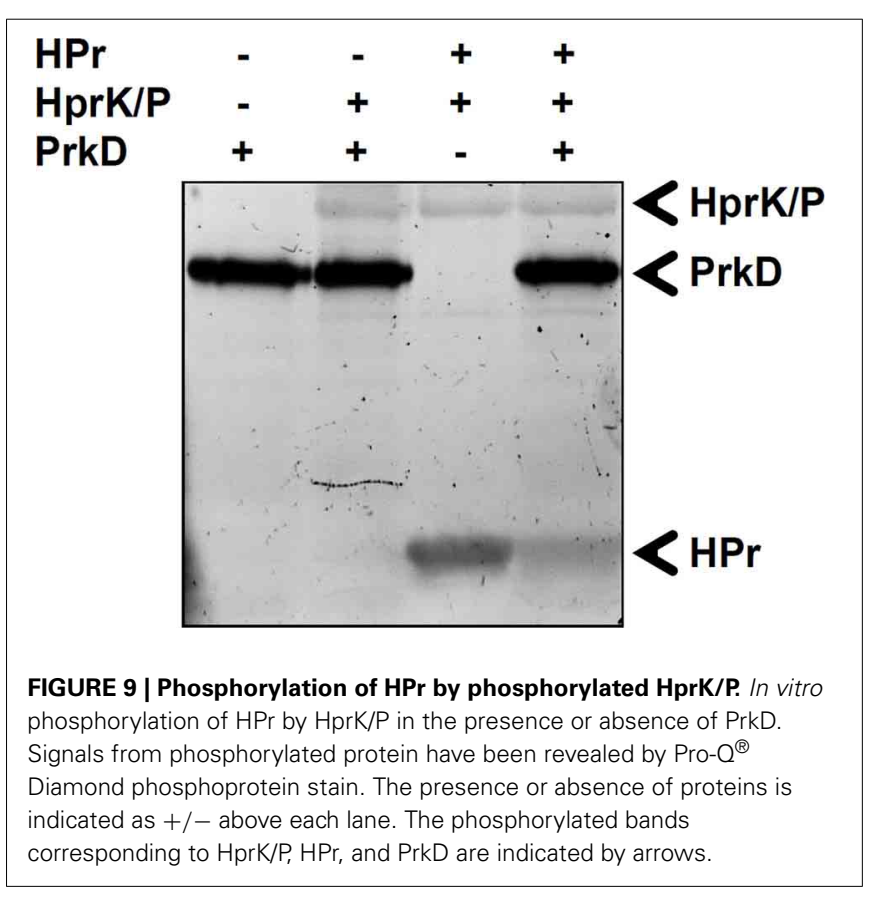

of this kinase in its 6xHis tag (Josef Deutscher, personal communication), and therefore additional phosphorylation by PrkD is not readily discernable. While this finding supports the notion that HprK/P activity is regulated by PrkD-dependent phosphorylation, its physiological relevance remains to be determined in vivo.

\section{CONCLUSIONS AND PERSPECTIVES}

Our global interactomics screen of the regulatory network based on serine/threonine/tyrosine phosphorylation in B. subtilis (Shi et al., unpublished results) revealed a high degree of connectivity among different classes of kinases, kinase activators, substrates, and phosphatases. Here we have explored whether the connectivity at the protein-protein interaction level may point to a functional interaction, i.e., cross-phosphorylation among the four classes of B. subtilis serine/threonine and tyrosine protein kinases. Our data suggest an even higher degree of connectivity than the interactomics studies, with all tested kinases engaging in cross phosphorylation, either as donors or recipients. Moreover, the identity of residues phosphorylated on recipient kinases in most cases supports the notion that phosphorylation of one kinase by another has a functional/regulatory consequence. The phosphorylated residues are situated in, or immediately adjacent to, protein-protein or protein-DNA interaction surfaces, activating loops or the kinase active sites. It is therefore likely that bacteria also possess kinase cascades similar to those described in eukarya (Marshall, 1994). Given the existing evidence on involvement of these kinases in complex phenomena such as bacterial cell cycle control and control of spore and biofilm development, this finding is not entirely unexpected. The kinase phosphorylation sites that we report here were not detected in the previous phosphoproteomics studies performed on B. subtilis (Macek et al., 2007; Ravikumar et al., 2014), which is not surprising due to 
the non-exhaustive nature of published bacterial phosphoproteomes. Nevertheless, the final verdict on the importance of kinase cross-phosphorylation and the putative kinase cascades in bacteria will have to come from in vivo studies.

\section{ACKNOWLEDGMENT}

This work was supported by grants from the Agence Nationale de la Recherche (2010-BLAN-1303-01 to IM and MFNG), the Federation pour la Recherche Medicale (to Ivan Mijakovic and Lei Shi), and the Chalmers University of Technology (to Ivan Mijakovic). We are grateful to Josef Deutscher for providing the B. subtilis HPr protein for in vitro kinase assays.

\section{REFERENCES}

Absalon, C., Obuchowski, M., Madec, E., Delattre, D., Holland, I. B., and Séror, S. J. (2009). CpgA, EF-Tu and the stressosome protein YezB are substrates of the Ser/Thr kinase/phosphatase couple, PrkC/PrpC, in Bacillus subtilis. Microbiology 155, 932-943. doi: 10.1099/mic.0.022475-0

Baer, C. E., Iavarone, A. T., Alber, T., and Sassetti, C. M. (2014). Biochemical and spatial coincidence in the provisional Ser/Thr protein kinase interaction network of Mycobacterium tuberculosis. J. Biol. Chem. 289, 20422-20433. doi: 10.1074/jbc.M114.559054

Barthe, P., Mukamolova, G. V., Roumestand, C., and Cohen-Gonsaud, M. (2010). The structure of PknB extracellular PASTA domain from Mycobacterium tuberculosis suggests a ligand-dependent kinase activation. Structure 18, 606-615. doi: 10.1016/j.str.2010.02.013

Bidnenko, V., Shi, L., Kobir, A., Ventroux, M., Pigeonneau, N., Henry, C., et al. (2013). Bacillus subtilis serine/threonine protein kinase YabT is involved in spore development via phosphorylation of a bacterial recombinase. Mol. Microbiol. 88, 921-935. doi: 10.1111/mmi.12233

Bordoli, L., Kiefer, F., Arnold, K., Benkert, P., Battey, J., and Schwede, T. (2009). Protein structure homology modeling using SWISS-MODEL workspace. Nat. Protoc. 4, 1-13. doi: 10.1038/nprot.2008.197

Burbulys, D., Trach, K. A., and Hoch, J. A. (1991). Initiation of sporulation in B. subtilis is controlled by a multicomponent phosphorelay. Cell 64, 545-552. doi: 10.1016/0092-8674(91)90238-T

Campbell, E. A., Masuda, S., Sun, J. L., Muzzin, O., Olson, C. A., Wang, S., et al. (2002). Crystal structure of the Bacillus stearothermophilus anti-sigma factor SpoIIAB with the sporulation sigma factor sigmaF. Cell 108, 795-807. doi: 10.1016/S0092-8674(02)00662-1

Colinge, J., César-Razquin, A., Huber, K., Breitwieser, F. P., Májek, P., and SupertiFurga, G. (2014). Building and exploring an integrated human kinase network: global organization and medical entry points. J. Proteomics 107, 113-127. doi: 10.1016/j.jprot.2014.03.028

Cousin, C., Derouiche, A., Shi, L., Pagot, Y., Poncet, S., and Mijakovic, I. (2013). Protein-serine/threonine/tyrosine kinases in bacterial signaling and regulation. FEMS Microbiol. Lett. 346, 11-19. doi: 10.1111/1574-6968.12189

Derouiche, A., Bidnenko, V., Grenha, R., Pigonneau, N., Ventroux, M., FranzWachtel, M., et al. (2013). Interaction of bacterial fatty-acid-displaced regulators with DNA is interrupted by tyrosine phosphorylation in the helix-turn-helix domain. Nucleic Acids Res. 41, 9371-9381. doi: 10.1093/nar/ gkt709

Gerwig, J., Kiley, T. B., Gunka, K., Stanley-Wall, N., and Stülke, J. (2014). The protein tyrosine kinases EpsB and PtkA differentially affect biofilm formation in Bacillus subtilis. Microbiology 160, 682-691. doi: 10.1099/mic.0. 074971-0

Goulian, M. (2010). Two-component signaling circuit structure and properties. Curr. Opin. Microbiol. 13, 184-189. doi: 10.1016/j.mib.2010.01.009

Grundner, C., Gay, L. M., and Alber, T. (2005). Mycobacterium tuberculosis serine/threonine kinases $\mathrm{PknB}, \mathrm{PknD}, \mathrm{PknE}$, and $\mathrm{PknF}$ phosphorylate multiple FHA domains. Protein Sci. 14, 1918-1921. doi: 10.1110/ps.051413405

Hanson, K. G., Steinhauer, K., Reizer, J., Hillen, W., and Stülke, J. (2002). HPr kinase/phosphatase of Bacillus subtilis: expression of the gene and effects of mutations on enzyme activity, growth and carbon catabolite repression. Microbiology 148, 1805-1811. Available online at: http://mic.sgmjournals.org/ content/148/6/1805.long
James, P., Halladay, J., and Craig, E. A. (1996). Genomic libraries and a host strain designed for highly efficient two-hybrid selection in yeast. Genetics 144, 1425-1436.

Jers, C., Kobir, A., Søndergaard, E. O., Jensen, P. R., and Mijakovic, I. (2011). Bacillus subtilis two-component system sensory kinase DegS is regulated by serine phosphorylation in its input domain. PLOS ONE 6:e14653. doi: 10.1371/journal.pone.0014653

Jers, C., Pedersen, M. M., Paspaliari, D. K., Schütz, W., Johnsson, C., Soufi, B., et al. (2010). Bacillus subtilis BY-kinase PtkA controls enzyme activity and localization of its protein substrates. Mol. Microbiol. 77, 287-299. doi: 10.1111/j.13652958.2010.07227.x

Joseph, P., Guiseppi, A., Sorokin, A., and Denizot, F. (2004). Characterization of the Bacillus subtilis YxdJ response regulator as the inducer of expression for the cognate ABC transporter YxdLM. Microbiology 150, 2609-2617. doi: 10.1099/ mic. $0.27155-0$

Kang, C. M., Vijay, K., and Price, C. W. (1998). Serine kinase activity of a Bacillus subtilis switch protein is required to transduce environmental stress signals but not to activate its target PP2C phosphatase. Mol. Microbiol. 30, 189-196. doi: 10.1046/j.1365-2958.1998.01052.x

Katoh, K., and Toh, H. (2008). Recent developments in the MAFFT multiple sequence alignment program. Brief Bioinform. 9, 286-298. doi: 10.1093/bib/bbn013

Kobir, A., Poncet, S., Bidnenko, V., Delumeau, O., Jers, C., Zouhir, S., et al. (2014). Phosphorylation of Bacillus subtilis gene regulator AbrB modulates its DNAbinding properties. Mol. Microbiol. 92, 1129-1141. doi: 10.1111/mmi.12617

Macek, B., Mijakovic, I., Olsen, J. V., Gnad, F., Kumar, C., Jensen, P. R., et al. (2007). The serine/threonine/tyrosine phosphoproteome of the model bacterium Bacillus subtilis. Mol. Cell. Proteom. 6, 697-707. doi: 10.1074/mcp.M600464MCP200

Madec, E., Laszkiewicz, A., Iwanicki, A., Obuchowski, M., and Séror, S. (2002). Characterization of a membrane-linked Ser/Thr protein kinase in Bacillus subtilis, implicated in developmental processes. Mol. Microbiol. 46, 571-586. doi: 10.1046/j.1365-2958.2002.03178.x

Márquez, J. A., Hasenbein, S., Koch, B., Fieulaine, S., Nessler, S., Russell, R. B., et al. (2002). Structure of the full-length HPr kinase/phosphatase from Staphylococcus xylosus at 1.95 A resolution: mimicking the product/substrate of the phospho transfer reactions. Proc. Natl. Acad. Sci. U.S.A. 99, 3458-3463. doi: 10.1073/pnas.052461499

Marshall, C. J. (1994). MAP kinase kinase kinase, MAP kinase kinase and MAP kinase. Curr. Opin. Genet. Dev. 4, 82-89. doi: 10.1016/0959-437X(94)90095-7

Masuda, S., Murakami, K. S., Wang, S., Anders Olson, C., Donigian, J., Leon, F., et al. (2004). Crystal structures of the ADP and ATP bound forms of the Bacillus anti-sigma factor SpoIIAB in complex with the anti-anti-sigma SpoIIAA. J. Mol. Biol. 340, 941-956. doi: 10.1016/j.jmb.2004.05.040

Mijakovic, I., Musumeci, L., Tautz, L., Petranovic, D., Edwards, R. A., Jensen, P. R., et al. (2005). In vitro characterization of the Bacillus subtilis protein tyrosine phosphatase YwqE. J. Bacteriol. 187, 3384-3390. doi: 10.1128/JB.187.10.33843390.2005

Mijakovic, I., Poncet, S., Boël, G., Maz,é, A., Gillet, S., Jamet, E., et al. (2003). Transmembrane modulator-dependent bacterial tyrosine kinase activates UDPglucose dehydrogenases. EMBO J. 22, 4709-4718. doi: 10.1093/emboj/cdg458

Min, K. T., Hilditch, C. M., Diederich, B., Errington, J., and Yudkin, M. D. (1993). Sigma F, the first compartment-specific transcription factor of B. subtilis, is regulated by an anti-sigma factor that is also a protein kinase. Cell 74, 735-742. doi: 10.1016/0092-8674(93)90520-Z

Molle, V., and Kremer, L. (2010). Division and cell envelope regulation by Ser/Thr phosphorylation: Mycobacterium shows the way. Mol. Microbiol. 75, 1064-1077. doi: 10.1111/j.1365-2958.2009.07041.x

Musumeci, L., Bongiorni, C., Tautz, L., Edwards, R. A., Osterman, A., Perego, M., et al. (2005). Low-molecular-weight protein tyrosine phosphatases of Bacillus subtilis. J. Bacteriol. 187, 4945-4956. doi: 10.1128/JB.187.14.49454956.2005

Nicolas, P., Mäder, U., Dervyn, E., Rochat, T., Leduc, A., Pigeonneau, N., et al. (2012). Condition-dependent transcriptome reveals high-level regulatory architecture in Bacillus subtilis. Science 335, 1103-1106. doi: 10.1126/science. 1206848

Noirot-Gros, M. F., Dervyn, E., Wu, L. J., Mervelet, P., Errington, J., Ehrlich, S. D., et al. (2002). An expanded view of bacterial DNA replication. Proc. Natl. Acad. Sci. U.S.A. 99, 8342-8347. doi: 10.1073/pnas.122040799 
Olivares-Illana, V., Meyer, P., Bechet, E., Gueguen-Chaignon, V., Soulat, D., Lazereg-Riquier, S., et al. (2008). Structural basis for the regulation mechanism of the tyrosine kinase CapB from Staphylococcus aureus. PLoS Biol. 6:e143. doi: 10.1371/journal.pbio.0060143

Pereira, S. F., Goss, L., and Dworkin, J. (2011). Eukaryote-like serine/threonine kinases and phosphatases in bacteria. Microbiol. Mol. Biol. Rev. 75, 192-212. doi: 10.1128/MMBR.00042-10

Petranovic, D., Grangeasse, C., Macek, B., Abdillatef, M., GueguenChaignon, V., Nessler, S., et al. (2009). Activation of Bacillus subtilis Ugd by the BY-kinase PtkA proceeds via phosphorylation of its residue tyrosine 70. J. Mol. Microbiol. Biotechnol. 17, 83-89. doi: 10.1159/000 206635

Pietack, N., Becher, D., Schmidl, S. R., Saier, M. H., Hecker, M., Commichau, F. M., et al. (2010). In vitro phosphorylation of key metabolic enzymes from Bacillus subtilis: PrkC phosphorylates enzymes from different branches of basic metabolism. J. Mol. Microbiol. Biotechnol. 18, 129-140. doi: 10.1159/0003 08512

Podgornaia, A. I., and Laub, M. T. (2013). Determinants of specificity in twocomponent signal transduction. Curr. Opin. Microbiol. 16, 156-162. doi: 10.1016/j.mib.2013.01.004

Rakette, S., Donat, S., Ohlsen, K., and Stehle, T. (2012). Structural analysis of Staphylococcus aureus serine/threonine kinase PknB. PLoS ONE 7:e39136. doi: 10.1371/journal.pone.0039136

Ravikumar, V., Shi, L., Krug, K., Derouiche, A., Jers, C., Cousin, C., et al. (2014) Quantitative phosphoproteome analysis of Bacillus subtilis reveals novel substrates of the kinase PrkC and phosphatase PrpC. Mol. Cell. Proteom. 13, 1965-1978. doi: 10.1074/mcp.M113.035949

Shah, I. M., Laaberki, M. H., Popham, D. L., and Dworkin, J. (2008). A eukaryotic-like Ser/Thr kinase signals bacteria to exit dormancy in response to peptidoglycan fragments. Cell 135, 486-496. doi: 10.1016/j.cell.2008. 08.039
Shi, L., Ji, B., Kolar-Znika, L., Boskovic, A., Jadeau, F., Combet, C., et al. (2014). Evolution of bacterial protein-tyrosine kinases and their relaxed specificity toward substrates. Genome Biol. Evol. 6, 800-817. doi: 10.1093/gbe/evu056

Yang, X., Kang, C. M., Brody, M. S., and Price, C. W. (1996). Opposing pairs of serine protein kinases and phosphatases transmit signals of environmental stress to activate a bacterial transcription factor. Genes Dev. 10, 2265-2275. doi: 10.1101/gad.10.18.2265

Young, T. A., Delagoutte, B., Endrizzi, J. A., Falick, A. M., and Alber, T. (2003). Structure of Mycobacterium tuberculosis PknB supports a universal activation mechanism for Ser/Thr protein kinases. Nat. Struct. Biol. 10, 168-174. doi: $10.1038 /$ nsb897

Conflict of Interest Statement: The authors declare that the research was conducted in the absence of any commercial or financial relationships that could be construed as a potential conflict of interest.

Received: 23 July 2014; accepted: 03 September 2014; published online: 17 September 2014.

Citation: Shi L, Pigeonneau N, Ravikumar V, Dobrinic P, Macek B, Franjevic D, Noirot-Gros M-F and Mijakovic I (2014) Cross-phosphorylation of bacterial serine/threonine and tyrosine protein kinases on key regulatory residues. Front. Microbiol. 5:495. doi: 10.3389/fmicb.2014.00495

This article was submitted to Microbial Physiology and Metabolism, a section of the journal Frontiers in Microbiology.

Copyright (c) 2014 Shi, Pigeonneau, Ravikumar, Dobrinic, Macek, Franjevic, NoirotGros and Mijakovic. This is an open-access article distributed under the terms of the Creative Commons Attribution License (CC BY). The use, distribution or reproduction in other forums is permitted, provided the original author(s) or licensor are credited and that the original publication in this journal is cited, in accordance with accepted academic practice. No use, distribution or reproduction is permitted which does not comply with these terms. 